\title{
O Financiamento da Educação na Constituição Federal de 1988 e suas Alterações até Abril de 2018
}

\author{
Nicholas Davies \\ Universidade Federal Fluminense (UFF), Niterói/RJ - Brasil
}

\section{Resumo}

O texto é uma compilação de disposições sobre financiamento educacional na Constituição Federal de 1988 e suas alterações até abril de 2018. Justifica-se porque muitos educadores não consideram as alterações que ela sofreu desde 1988, sobretudo pelas emendas constitucionais que desvincularam recursos da educação de 1994 a 2010, mesmo não alterando o art. 212 da CF, que define que governos devem aplicar um percentual mínimo dos impostos em educação.

Palavras-chave: Constituição Federal de 1988. Financiamento da Educação.

Education Funding in the Brazilian Federal Constitution of 1988 and Its Amendments up to April 2018

\section{Abstract}

The text is a compilation of educational funding provisions in the 1988 Brazilian Federal Constitution and its amendments up to April 2018. It is justified because many educators do not take into account the changes since 1988, particularly by the constitutional amendments that have reduced education funding between 1994 and 2010, even though they have not altered art. 212 of the Constitution, which establishes that the governments should spend a certain percentage of taxes on education.

Keywords: 1988 Brazilian Federal Constitution. Education Funding. 
O Financiamento da Educação na Constituição Federal de 1988 e suas Alterações até Abril de 2018

\section{O Financiamento da Educação na Constituição Federal de 1988 e suas Alterações até Abril de 2018}

O texto a seguir é uma compilação dos artigos sobre financiamento da educação na Constituição Federal (CF) de 1988 e seus acréscimos e alterações até abril de 2018. Duas são as justificativas para este levantamento. Uma é que muitos educadores e mesmo especialistas não consideram alterações e acréscimos que a CF sofreu desde 1988. Outra é que é muito comum eles se limitarem ao capítulo da educação e não observarem outros artigos da CF relacionados ao tema e localizados fora do capítulo da educação.

Um exemplo é o artigo 150, que prevê isenção de impostos de instituições de educação "sem fins lucrativos". Outro são as inúmeras emendas constitucionais que desvincularam recursos da manutenção e desenvolvimento do ensino (MDE) e saúde: EC de revisão No. 1, de 1994, a EC No. 10, de 1996, a EC No. 17, de 1997, a EC No. 27, de 2000, a EC No. 42, de 2003, a EC No. 56, de 2007. Graças à EC No. 59, de 2009, essa desvinculação foi extinta gradualmente em 2009 e 2010 e definitivamente em 2011, embora continuasse (não para a MDE) e fosse prorrogada em 2016, com a EC 93, cuja desvinculação não atinge a educação e saúde. Um terceiro exemplo é a EC No. 31, de 2000, que, ao criar o Fundo de Combate à Pobreza, previu que parte dos recursos (sem especificar o percentual) seria destinado à educação.

Por fim, a EC No. 95, de 2016, prevê que as despesas só poderão ser aumentadas com base no índice da inflação do ano anterior pelos próximos 20 anos, o que significa que o governo federal (e também estaduais e municipais, caso governadores e prefeitos tomem a iniciativa de fazerem o mesmo nas constituições estaduais e leis orgânicas municipais) não precisará aplicar em MDE o percentual mínimo dos impostos, previsto no art. 212 da CF, se tais gastos superarem os do ano anterior corrigidos pelo índice da inflação oficial. Esta EC No. 95, caso não revogada em breve, prejudicará a educação pública provavelmente com a mesma ou até maior intensidade que as emendas constitucionais que desvincularam parte dos recursos da educação de 1994 a 2010. Por isso, a proposta que resultou nesta EC 95 foi denominada por muitos de "PEC do fim do mundo".

É interessante observar que a imensa maioria das emendas educacionais que se referem ao financiamento são inseridas no Ato das Disposições Constitucionais Transitórias e tiveram/têm vigência mais longa que as disposições permanentes e na prática reduziram/reduzem os efeitos dessas disposições permanentes. Por exemplo, as ECs que desvincularam recursos de MDE vigoraram de 1994 a 2010 (16 anos), e a EC No. 95 está prevista para viger 20 anos.

Os trechos riscados foram alterados por emendas constitucionais, registradas em negrito e dentro de caixa.

\footnotetext{
As alterações introduzidas pela Emenda Constitucional de Revisão No. 1 (de 1\%/3/94) e pelas Emendas Constitucionais No.10 (de 4/3/96), No. 14 (de 12/9/96), No. 17 (de 22/11/97), No. 19 (de 4/6/98), No. 27 (de 21/3/00), No. 29 (de 13/9/00), No. 31 (de 14/12/00), prorrogada por tempo indeterminado pela EC No. 67 (de 22/12/2010), No. 42 (de 19/12/03), No. 53 (de 19/12/06), No. 56 (de 20/12/07), No. 59 (de 11/11/2009), No. 68 (de 21/12/2011), No. 85, de 26/2/2015, No. 93 (de 8/9/2016) e No. 95 (de 15/12/2016) estão em negrito e dentro de caixa. As disposições revogadas estão riscadas.
} 
Art. $7^{\circ}$. São direitos dos trabalhadores urbanos e rurais, além de outros que visem à melhoria de sua condição social:

XXV - assistência gratuita aos filhos e dependentes desde o nascimento até seis anos de idade em creches e pré-escolas.

XXV - assistência gratuita aos filhos e dependentes desde o nascimento até 5 (cinco) anos de idade em creches e pré-escolas; (alterado pela EC No. 53/2006)

Art. 30. Compete aos Municípios:

V1-manter, com a cooperação técnica e financeira da União e do Estado, programas de educação pré-escolar e de ensino fundamental.

VI - manter, com a cooperação técnica e financeira da União e do Estado, programas de educação infantil e de ensino fundamental; (alterado pela EC No. 53/2006)

Art. 34. A União não intervirá nos Estados nem no Distrito Federal, exceto para:

(...) VII - assegurar a observância dos seguintes princípios constitucionais:

(...) e) Aplicação do mínimo exigido da receita resultante de impostos estaduais, compreendida a proveniente de transferências, na manutenção e desenvolvimento do ensino. (acrescentado pela EC No. 14/1996)

e) Aplicação do mínimo exigido da receita resultante de impostos estaduais, compreendida a proveniente de transferências, na manutenção e desenvolvimento do ensino e nas ações e serviços públicos de saúde. (alterado pela EC No. 29, de 13/9/2000)

Art. 35. O Estado não intervirá em seus Municípios, nem a União nos Municípios localizados em Território Federal, exceto quando:

III - não tiver sido aplicado o mínimo exigido da receita municipal na manutenção e desenvolvimento do ensino;

III - não tiver sido aplicado o mínimo exigido da receita municipal na manutenção e desenvolvimento do ensino e nas ações e serviços públicos de saúde. (alterado pela EC No. 29/2000)

Art. 150. Sem prejuízo de outras garantias asseguradas ao contribuinte, é vedado à União, aos Estados, ao Distrito Federal e aos Municípios:

VI - instituir impostos sobre: 
c) patrimônio, renda ou serviços dos partidos políticos, inclusive suas fundações, das entidades sindicais dos trabalhadores, das instituições de educação e de assistência social sem fins lucrativos, atendidos os requisitos da lei;

$\S 4^{\circ}$ - As vedações expressas no inciso VI, alíneas b e c, compreendem somente o patrimônio, a renda e os serviços relacionados com as finalidades essenciais nelas mencionadas.

Capítulo III - Da Educação, da Cultura e do Desporto

Seção I - Da Educação

Art. 206. O ensino será ministrado com base nos seguintes princípios:

IV - gratuidade do ensino público em estabelecimentos oficiais;

$\forall$ - valorização dos profissionais do ensino, garantidos, na forma da lei, planos de carreira para o magistério público, com piso salarial profissional e ingresso exclusivamente por concurso público de provas e títulos, assegurado regime jurídico único para todas as instituições mantidas pela União;

V - valorização dos profissionais do ensino, garantidos, na forma da lei, planos de carreira para o magistério público, com piso salarial profissional e ingresso exclusivamente por concurso público de provas e títulos (alterado pela EC No. 19/1998)

V - valorização dos profissionais da educação escolar, garantidos, na forma da lei, planos de carreira, com ingresso exclusivamente por concurso público de provas e títulos, aos das redes públicas; (alterado pela EC No. 53/2006)

VIII - piso salarial profissional nacional para os profissionais da educação escolar pública, nos termos de lei federal.

Parágrafo único. A lei disporá sobre as categorias de trabalhadores considerados profissionais da educação básica e sobre a fixação de prazo para a elaboração ou adequação de seus planos de carreira, no âmbito da União, dos Estados, do Distrito Federal e dos Municípios. (acrescentado pela EC No. 53/2006)

Art. 207. As universidades gozam de autonomia didático-científica, administrativa e de gestão financeira e patrimonial, e obedecerão ao princípio de indissociabilidade entre ensino, pesquisa e extensão.

Art. 208. O dever do Estado com a educação será efetivado mediante a garantia de:

t-ensino fundamental, obrigatório e gratuito, inclusive para os que a ele não tiveram acesso na idade própria; 
I-ensino fundamental, obrigatório e gratuito, assegurada, inclusive, sua oferta gratuita para todos os que a ele não tiverem acesso na idade própria; (alterado pela EC No. 14/1996)

I - educação básica obrigatória e gratuita dos 4 (quatro) aos 17 (dezessete) anos de idade, assegurada inclusive sua oferta gratuita para todos os que a ela não tiveram acesso na idade própria; (alterado pela EC No. 59/2009, que prevê a sua implementação progressiva, até 2016, nos termos do Plano Nacional de Educação, com apoio técnico e financeiro da União).

II - progressiva extensão da obrigatoriedade e gratuidade ao ensino médio;

II - progressiva universalização do ensino médio gratuito; (alterado pela EC No. 14/1996)

$\S 1^{\circ}$ - O acesso ao ensino obrigatório e gratuito é direito público subjetivo.

Art. 211. A União, os Estados, o Distrito Federal e os Municípios organizarão em regime de colaboração seus sistemas de ensino.

$\S 1^{\circ}$ - A União organizará e financiará o sistema federal de ensino e o dos Territórios, e prestará assistência técnica e financeira aos Estados, ao Distrito Federale aos Municípios para o desenvolvimento de seus sistemas de ensino e o atendimento prioritário à escolaridade obrigatória.

$\S 1^{\circ}$ - A União organizará o sistema federal de ensino e dos Territórios, financiará as instituições de ensino públicas federais e exercerá, em matéria educacional, função redistributiva e supletiva, de forma a garantir equalização de oportunidades educacionais e padrão mínimo de qualidade do ensino mediante assistência técnica e financeira aos Estados, ao Distrito Federal e aos Municípios. (alterado pela EC No. 14/1996)

Art. 212. A União aplicará, anualmente, nunca menos de dezoito, e os Estados, o Distrito Federal e os Municípios, vinte e cinco por cento, no mínimo, da receita resultante de impostos, compreendida a proveniente de transferências, na manutenção e desenvolvimento do ensino. $\S 1^{\circ}$ - A parcela da arrecadação de impostos transferida pela União aos Estados, ao Distrito Federal e aos Municípios, ou pelos Estados aos respectivos Municípios, não é considerada, para efeito do cálculo previsto neste artigo, receita do governo que a transferir.

$\S 2^{\circ}$ - Para efeito do cumprimento do disposto no caput deste artigo, serão considerados os sistemas de ensino federal, estadual e municipal e os recursos aplicados na forma do art. 213. $\S 3^{\circ}$ - A distribuição dos recursos públicos assegurará prioridade ao atendimento das necessidades do ensino obrigatório, nos termos do plano nacional de educação. 
$\S 3^{\circ}$ - A distribuição dos recursos públicos assegurará prioridade ao atendimento das necessidades do ensino obrigatório, no que se refere à universalização, garantia de padrão de qualidade e equidade, nos termos do plano nacional de educação. (alterado pela EC No. 59/2009)

$\S 4^{\circ}$ - Os programas suplementares de alimentação e assistência à saúde previstos no art. 208, VII, serão financiados com recursos provenientes de contribuições sociais e outros recursos orçamentários.

$\S 5^{\circ}$-Oensino fundamental público terá como fonte adicional de financiamento a contribuição social do salário-educação, recolhida, na forma da lei, pelas empresas, que dela poderão deduzir a aplicação realizada no ensino fundamental de seus empregados e dependentes.

$\S 5^{\circ}$ - O ensino fundamental público terá como fonte adicional de financiamento a contribuição social do salário-educação, recolhida pelas empresas, na forma da lei. (alterado pela EC No. 14/1996)

$\S 5^{\circ}$ - A educação básica pública terá como fonte adicional de financiamento a contribuição social do salário-educação, recolhida pelas empresas na forma da lei. (alterado pela EC No. 53/2006)

$\$ 6^{\circ}$ - As cotas estaduais e municipais da arrecadação da contribuição social do salárioeducação serão distribuídas proporcionalmente ao número de alunos matriculados na educação básica nas respectivas redes públicas de ensino. (acrescentado pela EC No. $53 / 2006)$

Art. 213. Os recursos públicos serão destinados às escolas públicas, podendo ser dirigidos a escolas comunitárias, confessionais ou filantrópicas, definidas em lei, que

I - comprovem finalidade não-lucrativa e apliquem seus excedentes financeiros em educação;

II - assegurem a destinação de seu patrimônio a outra escola comunitária, filantrópica ou confessional, ou ao Poder Público, no caso de encerramento de suas atividades.

$\S 1^{\circ}$ - Os recursos de que trata este artigo poderão ser destinados a bolsas de estudo para o ensino fundamental e médio, na forma da lei, para os que demonstrarem insuficiência de recursos, quando houver falta de vagas e cursos regulares da rede pública na localidade da residência do educando, ficando o Poder Público obrigado a investir prioritariamente na expansão de sua rede na localidade.

$\S 2^{\circ}$ - As atividades universitárias de pesquisa e extensão poderão receber apoio financeiro do Poder Público.

$\S 2^{\circ}$ As atividades de pesquisa, de extensão e de estímulo e fomento à inovação realizadas por universidades e/ou por instituições de educação profissional e tecnológica poderão receber apoio financeiro do Poder Público. (alterado pela EC No. 85/2015) 
Art. 214. A lei estabelecerá o plano nacional de educação, de duração plurianual, visandoà articulação e ao desenvolvimento do ensino em seus diversos níveis e à integração das ações do Poder Público que conduzam à:

Art. 214. A lei estabelecerá o plano nacional de educação, de duração decenal, com o objetivo de articular o sistema nacional de educação em regime de colaboração e definir diretrizes, objetivos, metas e estratégias de implementação para assegurar a manutenção e desenvolvimento do ensino em seus diversos níveis, etapas e modalidades por meio de ações integradas dos poderes públicos das diferentes esferas federativas que conduzam a: (alterado pela EC No. 59/2009)

VI - estabelecimento de meta de aplicação de recursos públicos em educação como proporção do produto interno bruto. (acrescentado pela EC No. 59/2009)

Art. $218-\S 5^{\circ}$ - É facultado aos Estados e ao Distrito Federal vincular parcela de sua receita orçamentária a entidades públicas de fomento ao ensino e à pesquisa científica e tecnológica.

Art. 219-A. A União, os Estados, o Distrito Federal e os Municípios poderão firmar instrumentos de cooperação com órgãos e entidades públicos e com entidades privadas, inclusive para o compartilhamento de recursos humanos especializados e capacidade instalada, para a execução de projetos de pesquisa, de desenvolvimento científico e tecnológico e de inovação, mediante contrapartida financeira ou não financeira assumida pelo ente beneficiário, na forma da lei. (acrescentado pela EC No. 85/2015)

Das Disposições Constitucionais Gerais

Art. 242. O princípio do Art. 206, IV [a gratuidade nas escolas oficiais], não se aplica às instituições educacionais oficiais criadas por lei estadual ou municipal e existentes na data da promulgação desta Constituição, que não sejam total ou preponderantemente mantidas com recursos públicos.

Ato das Disposições Constitucionais Transitórias

Art. 60. Nos dez primeiros anos da promulgação da Constituição, o Poder Público desenvolverá esforços, com a mobilização de todos os setores organizados da sociedade e com a aplicação de, pelo menos, cinqüenta por cento dos recursos a que se refere 0 art. 212 da Constituição, para eliminar 0 analfabetismo e universalizar o ensino fundamental. 
Art. 60. Nos dez primeiros anos da promulgação desta Emenda, os Estados, o Distrito Federal e os Municípios destinarão não menos de sessenta por cento dos recursos-a que refere 0 art. 212 da Constituição Federal à manutenção e ao desenvolvimento do ensino fundamental, com o objetivo de assegurar universalização de seu atendimento e a remuneração condigna do magistério. (alterado pela EC 14/1996)

$\S 1^{\circ}$ - A distribuição de responsabilidades e recursos entre os Estados e seus Municípios, a ser concretizada com parte dos recursos definidos neste artigo, na forma do disposto no art. 211 da Constituição Federal, é assegurada mediante a criação, no âmbito de cada Estado e do Distrito Federal, de um Fundo de Manutenção e Desenvolvimento do Ensino-Fundamental e de Valorização do Magistério, de natureza contábil.

$\S 2^{\circ}$-O Fundo referido no parágrafo anterior será constituído por, pelo menos, quinze por cento dos recursos a que se referem os art. 155, incisoll, 158, inciso IV, e 159, inciso I, alíneas a e b, e inciso II, da Constituição Federal, e será distribuído entre cada Estado e seus municípios, proporcionalmente ao número de alunos nas respectivas redes de ensino fundamental.

$\S 3^{\circ}$ - A União complementará os recursos dos Fundos a que se refere o par. $1^{\circ}$, sempre que, em cada Estado e no Distrito Federal, seu valor por aluno não alcançar o mínimo definido nacionalmente.

$\S 4^{\circ}$ - A União, os Estados, o Distrito Federal e os Municípios ajustarão progressivamente, em um prazo de cinco anos, suas contribuições ao Fundo, de forma a garantir um valor por aluno correspondente a um padrão mínimo de qualidade de ensino, definido nacionalmente.

$\$ 5^{\circ}$ - Uma proporção não inferior a sessenta por cento dos recursos de cada Fundo referido no par. $1^{\circ}$ será destinada ao pagamento dos professores do ensino fundamental em efetivo exercício no magistério.

$\$ 6^{\circ}$ - A União aplicará na erradicação do analfabetismo e na manutenção do ensino fundamental, inclusive na complementação a que se refere o par. $3^{\circ}$, nunca menos que o equivalente a trinta por cento dos recursos a que se refere- o caput do art. 212 da Constituição Federal.

$\$ 7^{\circ}$-A lei disporá sobre a organização dos Fundos, a distribuição proporcional de seus recursos, sua fiscalização e controle, bem como sobre a forma de cálculo do valor mínimo nacional por aluno. (alterado e acrescentado pela EC No. 14/1996)

Art. 60. Até $014^{\circ}$ (décimo quarto) ano a partir da promulgação desta Emenda Constitucional, os Estados, o Distrito Federal e os Municípios destinarão parte dos recursos a que se refere o caput do art. 212 da Constituição Federal à manutenção e desenvolvimento da educação básica e à remuneração condigna dos trabalhadores da educação, respeitadas as seguintes disposições:

I - a distribuição dos recursos e de responsabilidades entre o Distrito Federal, os Estados e seus Municípios é assegurada mediante a criação, no âmbito de cada Estado e do Distrito Federal, de um Fundo de Manutenção e Desenvolvimento da Educação Básica e de Valorização dos Profissionais da Educação - FUNDEB, de natureza contábil; 
II - os Fundos referidos no inciso I do caput deste artigo serão constituídos por $20 \%$ (vinte por cento) dos recursos a que se referem os incisos I, II e III do art. 155; o inciso II do caput do art. 157; os incisos II, III e IV do caput do art. 158; e as alíneas a e b do inciso I e o inciso II do caput do art. 159, todos da Constituição Federal, e distribuídos entre cada Estado e seus Municípios, proporcionalmente ao número de alunos das diversas etapas e modalidades da educação básica presencial, matriculados nas respectivas redes, nos respectivos âmbitos de atuação prioritária estabelecidos nos $\S \S$ $2^{\circ}$ e $3^{\circ}$ do art. 211 da Constituição Federal;

III - observadas as garantias estabelecidas nos incisos I, II, III e IV do caput do art. 208 da Constituição Federal e as metas de universalização da educação básica estabelecidas no Plano Nacional de Educação, a lei disporá sobre:

a) a organização dos Fundos, a distribuição proporcional de seus recursos, as diferenças e as ponderações quanto ao valor anual por aluno entre etapas e modalidades da educação básica e tipos de estabelecimento de ensino;

b) a forma de cálculo do valor anual mínimo por aluno;

c) os percentuais máximos de apropriação dos recursos dos Fundos pelas diversas etapas e modalidades da educação básica, observados os arts. 208 e 214 da Constituição Federal, bem como as metas do Plano Nacional de Educação;

d) a fiscalização e o controle dos Fundos;

e) prazo para fixar, em lei específica, piso salarial profissional nacional para os profissionais do magistério público da educação básica;

IV - os recursos recebidos à conta dos Fundos instituídos nos termos do inciso I do caput deste artigo serão aplicados pelos Estados e Municípios exclusivamente nos respectivos âmbitos de atuação prioritária, conforme estabelecido nos $\S \S 2^{\circ}$ e $3^{\circ}$ do art. 211 da Constituição Federal;

V - a União complementará os recursos dos Fundos a que se refere o inciso II do caput deste artigo sempre que, no Distrito Federal e em cada Estado, o valor por aluno não alcançar o mínimo definido nacionalmente, fixado em observância ao disposto no inciso VII do caput deste artigo, vedada a utilização dos recursos a que se refere o $\S 5^{\circ}$ do art. 212 da Constituição Federal;

$\mathrm{VI}$ - até $10 \%$ (dez por cento) da complementação da União prevista no inciso V do caput deste artigo poderá ser distribuída para os Fundos por meio de programas direcionados para a melhoria da qualidade da educação, na forma da lei a que se refere o inciso III do caput deste artigo;

VII - a complementação da União de que trata o inciso V do caput deste artigo será de, no mínimo:

a) $\mathbf{R} \$ \mathbf{2} .000 .000 .000,00$ (dois bilhões de reais), no primeiro ano de vigência dos Fundos;

b) $\mathbf{R} \$ \mathbf{3 . 0 0 0 . 0 0 0 . 0 0 0 , 0 0}$ (três bilhões de reais), no segundo ano de vigência dos Fundos;

c) $R \$ 4.500 .000 .000,00$ (quatro bilhões e quinhentos milhões de reais), no terceiro ano de vigência dos Fundos;

d) $10 \%$ (dez por cento) do total dos recursos a que se refere o inciso II do caput deste artigo, a partir do quarto ano de vigência dos Fundos; 
VIII - a vinculação de recursos à manutenção e desenvolvimento do ensino estabelecida no art. 212 da Constituição Federal suportará, no máximo, 30\% (trinta por cento) da complementação da União, considerando-se para os fins deste inciso os valores previstos no inciso VII do caput deste artigo;

IX - os valores a que se referem as alíneas a, b, e c do inciso VII do caput deste artigo serão atualizados, anualmente, a partir da promulgação desta Emenda Constitucional, de forma a preservar, em caráter permanente, o valor real da complementação da União; $X$ - aplica-se à complementação da União o disposto no art. 160 da Constituição Federal; XI - o não-cumprimento do disposto nos incisos V e VII do caput deste artigo importará crime de responsabilidade da autoridade competente;

XII - proporção não inferior a $60 \%$ (sessenta por cento) de cada Fundo referido no inciso I do caput deste artigo será destinada ao pagamento dos profissionais do magistério da educação básica em efetivo exercício.

$\S 1^{\circ}$ A União, os Estados, o Distrito Federal e os Municípios deverão assegurar, no financiamento da educação básica, a melhoria da qualidade de ensino, de forma a garantir padrão mínimo definido nacionalmente.

$\S 2^{\circ} \mathrm{O}$ valor por aluno do ensino fundamental, no Fundo de cada Estado e do Distrito Federal, não poderá ser inferior ao praticado no âmbito do Fundo de Manutenção e Desenvolvimento do Ensino Fundamental e de Valorização do Magistério - FUNDEF, no ano anterior à vigência desta Emenda Constitucional.

$\S 3^{\circ} \mathrm{O}$ valor anual mínimo por aluno do ensino fundamental, no âmbito do Fundo de Manutenção e Desenvolvimento da Educação Básica e de Valorização dos Profissionais da Educação - FUNDEB, não poderá ser inferior ao valor mínimo fixado nacionalmente no ano anterior ao da vigência desta Emenda Constitucional.

$\S 4^{\circ}$ Para efeito de distribuição de recursos dos Fundos a que se refere o inciso I do caput deste artigo, levar-se-á em conta a totalidade das matrículas no ensino fundamental e considerar-se-á para a educação infantil, para o ensino médio e para a educação de jovens e adultos $1 / 3$ (um terço) das matrículas no primeiro ano, 2/3 (dois terços) no segundo ano e sua totalidade a partir do terceiro ano.

$\S 5^{\circ} \mathrm{A}$ porcentagem dos recursos de constituição dos Fundos, conforme o inciso II do caput deste artigo, será alcançada gradativamente nos primeiros 3 (três) anos de vigência dos Fundos, da seguinte forma:

I - no caso dos impostos e transferências constantes do inciso II do caput do art. 155; do inciso IV do caput do art. 158; e das alíneas a e b do inciso I e do inciso II do caput do art. 159 da Constituição Federal:

a) $16,66 \%$ (dezesseis inteiros e sessenta e seis centésimos por cento), no primeiro ano;

b) $\mathbf{1 8 , 3 3 \%}$ (dezoito inteiros e trinta e três centésimos por cento), no segundo ano;

c) $\mathbf{2 0 \%}$ (vinte por cento), a partir do terceiro ano;

II - no caso dos impostos e transferências constantes dos incisos I e III do caput do art. 155; do inciso II do caput do art. 157; e dos incisos II e III do caput do art. 158 da Constituição Federal:

a) $6,66 \%$ (seis inteiros e sessenta e seis centésimos por cento), no primeiro ano; 
b) $13,33 \%$ (treze inteiros e trinta e três centésimos por cento), no segundo ano;

c) $\mathbf{2 0 \%}$ (vinte por cento), a partir do terceiro ano. (alterado pela EC No. 53/2006)

Art. 61. As entidades educacionais a que se refere o art. 213, bem como as fundações de ensino e pesquisa cuja criação tenha sido autorizada por lei, que preencham os requisitos dos incisos I e II do referido artigo e que, nos últimos três anos, tenham recebido recursos públicos, poderão continuar a recebê-los, salvo disposição legal em contrário.

Art. 71. Fica instituído, nos exercícios financeiros de 1994 e 1995, o Fundo Social de Emergência, com o objetivo de saneamento da Fazenda Pública Federal e de estabilização-econômica, cujos recursos serão aplicados no-custeio das ações-dos sistemas de saúde e educação [...] (acrescentado pela EC de Revisão No. 1/1994)

Art. 71. Fica instituído, nos exercícios financeiros de 1994 e 1995, bem assim no período de $1^{\circ}$ de janeiro de 1996 a 30 de junho de 1997 , o Fundo Social de Emergência, com o objetivo de saneamento da Fazenda Pública Federal e de estabilização econômica, cujos recursos serão aplicados prioritariamente no custeio dos sistemas de saúde e educação [...]

$\S 2^{\circ} \mathrm{O}$ Fundo criado por este artigo passa a ser denominado Fundo de Estabilização Fiscal a partir do início do exercício financeiro de 1996. (alterado pela EC No. 10/1996)

Art. 71. É instituído, nos exercícios financeiros de 1994 e 1995, bem assim nos períodos de $1^{\circ}$ de janeiro de 1996 a 30 de junho de 1997 e $1^{\circ}$ de julho de 1997 a 31 de dezembro de 1999, o Fundo Social de Emergência, com o objetivo de saneamento da Fazenda Pública Federal e de estabilização econômica, cujos recursos serão aplicados prioritariamente no custeio dos sistemas de saúde e educação, incluindo a complementação de recursos de que trata $\circ \S 3^{\circ}$ do art. 60 do Ato das Disposições Constitucionais Transitórias [a complementação federal para o Fundef] [...] (alterado pela EC No. 17/1997)

Art. 72. Integram o Fundo Social de Emergência:

I - o produto da arrecadação do imposto sobre renda e proventos de qualquer natureza incidente na fonte sobre pagamentos efetuados, a qualquer título, pela União, inclusive suas autarquias e fundações;

II - a parcela do produto da arrecadação do imposto sobre propriedade territorial rural, do imposto sobre renda e proventos de qualquer natureza e do imposto sobre operações de crédito, câmbio e seguro, ou relativas a títulos ou valores mobiliários (...); III - a parcela do produto da arrecadação resultante da elevação da alíquota da contribuição social sobre o lucro dos contribuintes a que se refere 0 \& $1^{\circ}$ do art. 22 da Lei $n^{\circ}$ 8.212, de 24 de julho de 1991, a qual, nos exercícios financeiros de 1994 e 1995, passa a ser de trinta por cento, mantidas as demais normas da Lei $n^{\circ} 7.689$, de 15 de 
dezembro de 1988;

IV - vinte por cento da arrecadação de todos os impostos e contribuições da União, excetuado o previsto nos incisos I, II ell..

$(\ldots)$

$V$ a parcela do produto da arrecadação da contribuição de que trata a Lei Complementar $\mathrm{n} \cdot .^{0} 7$, de 7 de setembro de 1970 , devida pelas pessoas jurídicas a que se refere o inciso III deste artigo, a qual será calculada, nos exercícios financeiros de 1994 e 1995, mediante a aplicação da alíquota de setenta e cinco centésimos por cento sobre a receita bruta operacional, como definida na legislação do imposto sobre renda e proventos de qualquer natureza;

VI - outras receitas previstas em lei específica. http://www.planalto.gov.br/ccivil_03/Constituicao/Emendas/ECR/ecr1.htm - art1

$\S 1 .^{\circ}$ As alíquotas e a base de cálculo previstas nos incisos III e V aplicar-se-ão a partir do primeiro dia do mês seguinte aos noventa dias posteriores à promulgação desta Emenda.

$\$ 2^{\circ}$. As parcelas de que tratam os incisos I, II, III e $V$ serão previamente deduzidas da base de cálculo de qualquer vinculação ou participação constitucional ou legal, não se Ihes aplicando o disposto nos arts. 158, II, 159, 212 e 239 da Constituição.

\$ $3^{\circ}$. A parcela de que trata o inciso IV será previamente deduzida da base de cálculo das vinculações ou participações constitucionais previstas nos arts. $153, \S 5^{\circ}, 157$, II, 158, II, 212, e 239 da Constituição. (...)

$\$ 4^{\circ} 0$ disposto no parágrafo anterior não se aplica aos recursos previstos no art. 159 da Constituição.

$\$ 5^{\circ}$ A parcela dos recursos provenientes do imposto sobre propriedade territorial rural e do imposto sobre renda e proventos de qualquer natureza, destinada ao Fundo Social de Emergência, nos termos do inciso ll deste artigo, não poderá exceder:

1-no caso do imposto sobre propriedade territorial rural, a oitenta e seis inteiros e dois décimos por cento do total do produto da sua arrecadação;

II- no caso do imposto sobre renda e proventos de qualquer natureza, a cinco inteiros e seis décimos por cento do total do produto da sua arrecadação. (acrescentado pela EC de Revisão No.1/1994)

Art. 72. Integram o Fundo Social de Emergência:

$[\ldots]$

II - a parcela do produto da arrecadação do imposto sobre renda e proventos de qualquer natureza e do imposto sobre operações de crédito, câmbio e seguro, ou relativas a títulos e valores mobiliários, decorrente das alterações produzidas pela Lei $n^{\circ} 8.894$, de 21 de junho de 1994, e pelas Leis $n^{\circ} s 8.849$ e 8.848, ambas de 28 de janeiro de 1994, e modificações posteriores; [...]

III - a parcela do produto da arrecadação resultante da elevação da alíquota da contribuição social sobre o lucro dos contribuintes a que se refere 0 \$ $1^{\circ}$ do Art. 22 da Lei $n^{\circ}$ 8.212, de 24 de julho de 1991, a qual, nos exercícios financeiros de 1994 e 1995, 
bem assim no período de $1^{\circ}$ de janeiro de 1996 a 30 de junho de 1997, passa a ser de trinta por cento, sujeita a alteração por lei ordinária, mantidas as demais normas da Lei $n^{\circ} 7.689$, de 15 de dezembro de 1988;

IV - vinte por cento da arrecadação de todos os impostos e contribuições da União, já instituídos ou a serem criados, excetuado o previsto nos incisos I, II e III, observado o disposto nos parágrafos $3^{\circ}$ e $4^{\circ}$. [...]

$V$ - a parcela do produto da arrecadação da contribuição de que trata a Lei Complementar $n^{0} 7$, de 7 de setembro de 1970, devida pelas pessoas jurídicas a que se refere o incisolll deste artigo, a qual será calculada, nos exercícios financeiros de 1994 e 1995, bem assim no período de $1^{\circ}$ de janeiro de 1996 a 30 de junho de 1997 , mediante a aplicação da alíquota de setenta e cinco centésimos por cento, sujeita a alteração por lei ordinária, sobre a receita bruta operacional, como definida na legislação do imposto sobre renda e proventos de qualquer natureza; $e$ "

$\S 2^{\circ}$. As parcelas de que tratam os incisos I, II, III e V serão previamente deduzidas da base de cálculo de qualquer vinculação ou participação constitucional ou legal, não se Ihes aplicando o disposto nos arts. 159, 212 e 239 da Constituição.

$\S 3^{\circ}$. A parcela de que trata 0 inciso IV será previamente deduzida da base de cálculo das vinculações ou participações constitucionais previstas nos arts. $153, \S 5^{\circ}, 157$, II, 212, e 239 da Constituição.

$\S 4^{\circ}$. O disposto no parágrafo anterior não se aplica aos recursos previstos nos arts. 158, II, e 159 da Constituição.

$\S 5^{\circ}$ A parcela dos recursos provenientes do imposto sobre renda e proventos de qualquer natureza, destinada ao Fundo Social de Emergência, nos termos do inciso II deste artigo, não poderá exceder a cinco inteiros e seis décimos por cento do total do produto da sua arrecadação. (alterado pela EC No. 10/1996).

V - a parcela do produto da arrecadação da contribuição de que trata a Lei Complementar $n^{\circ} 7$, de 7 de setembro de 1970, devida pelas pessoas jurídicas a que se refere o inciso III deste artigo, a qual será calculada, nos exercícios financeiros de 1994 a 1995, bem assim nos períodos de $1^{\circ}$ de janeiro de 1996 a 30 de junho de 1997 e de $1^{\circ}$ de julho de 1997 a 31 de dezembro de 1999, mediante a aplicação da alíquota de setenta e cinco centésimos por cento, sujeita a alteração por lei ordinária posterior, sobre a receita bruta operacional, como definida na legislação do imposto sobre renda e proventos de qualquer natureza. (alterado pela EC No. 17, de 1997)

Art. 76. É desvinculado de órgão, fundo ou despesa, no período de 2000 a 2003, vinte por cento da arrecadação de impostos e contribuições sociais da União, já instituídos ou que vierem a ser criados no referido período, seus adicionais e respectivos acréscimos legais.

$\$ 1^{\circ} 0$ disposto no caput deste artigo não reduzirá a base de cálculo das transferências a Estados, Distrito Federal e Municípios na formas dos arts. $153, \S 5 \circ, 157,1 ; 158,1$ e II; e 159, la e b, ell, da Constituição (...) 
$\S 2^{\circ}$ Excetua-se da desvinculação de que trata o caput deste artigo a arrecadação da contribuição social do salário-educação a que se refere 0 art. $212, \S 5^{\circ}$, da Constituição. (acréscimos e alterações introduzidas pela EC No. 27/2000)

Art. 76. É desvinculado de órgão, fundo ou despesa, no período de 2003-a 2007, vinte por cento da arrecadação da União de impostos, contribuições sociais e de intervenção no domínio econômico, já instituídos ou que vierem a ser criados no referido período, seus adicionais e respectivos acréscimos legais.

$\$ 1^{\circ}$ O disposto no caput deste artigo não reduzirá a base de cálculo das transferências a Estados, Distrito Federal e Municípios na forma dos arts. $153, \S 5 \circ ; 157,1 ; 158$, 1 e II; e 159, I, a e b; e II, da Constituição, bem como a base de cálculo das destinações a que se refere o-art. 159,1, c, da Constituição-(alterado pela EC No. 42, de 2003)

Art. 76. É desvinculado de órgão, fundo ou despesa, até 31 de dezembro de $2011,20 \%$ (vinte por cento) da arrecadação da União de impostos, contribuições sociais e de intervenção no domínio econômico, já instituídos ou que vierem a ser criados até a referida data, seus adicionais e respectivos acréscimos legais.

(Alterado pela EC No. 56, de 2007. Em 2009 e 2010 a EC 59, de 2009, diminuiu parcialmente esta desvinculação de recursos para a educação. Em 2011 a desvinculação foi suprimida definitivamente).

§ $3^{\circ}$ - Para efeito do cálculo dos recursos para manutenção e desenvolvimento do ensino de que trata 0 art. 212 da Constituição, o percentual referido no caput deste artigo será de $12,5 \%$ (doze inteiros e cinco décimos por cento) no exercício de 2009, 5\% (cinco por cento) no exercício de 2010, e nulo no exercício de 2011. (parágrafo acrescentado pela EC No. 59 e que vigorou em 2009 e 2010)

Art. 76. São desvinculados de órgão, fundo-ou despesa, até 31 de dezembro de 2015, $\mathbf{2 0 \%}$ (vinte por cento) da arrecadação da União de impostos, contribuições sociais e de intervenção no domínio econômico, já instituídos ou que vierem a ser criados até a referida data, seus adicionais e respectivos acréscimos legais.

$\$ 1^{\circ} 0$ disposto no caput não reduzirá a base de cálculo das transferências a Estados; Distrito Federal e Municípios, na forma do $\$ 5^{\circ}$ do art. 153, do incisol do art. 157 , dos incisos I ell do art. 158 e das alíneas a, be d do inciso le do inciso II do art. 159 da Constituição Federal, nem a base de cálculo das destinações a que se refere a alínea $c$ do incisol do art. 159 da Constituição Federal..

$2^{\circ}$ Excetua-se da desvinculação de que trata o caput a arrecadação da contribuição social do salário-educação a que se refere o parágrafo $5^{\circ}$ do art. 212 da Constituição Federal. 
$\S 3^{\circ}$ Para efeito do cálculo dos recursos para manutenção e desenvolvimento do ensino de que trata-o art. 212 da-Constituição-Federal, o percentual referido no caput será nulo. (alterado pela EC No. 68/2011)

Art. 76. São desvinculados de órgão, fundo ou despesa, até 31 de dezembro de 2023, $30 \%$ (trinta por cento) da arrecadação da União relativa às contribuições sociais, sem prejuízo do pagamento das despesas do Regime Geral da Previdência Social, às contribuições de intervenção no domínio econômico e às taxas, já instituídas ou que vierem a ser criadas até a referida data. (alterado pela EC No. 93/2016)

Art. 76-A. São desvinculados de órgão, fundo ou despesa, até 31 de dezembro de 2023, $30 \%$ (trinta por cento) das receitas dos Estados e do Distrito Federal relativas a impostos, taxas e multas, já instituídos ou que vierem a ser criados até a referida data, seus adicionais e respectivos acréscimos legais, e outras receitas correntes.

Parágrafo único. Excetuam-se da desvinculação de que trata o caput:

I - recursos destinados ao financiamento das ações e serviços públicos de saúde e à manutenção e desenvolvimento do ensino de que tratam, respectivamente, os incisos II e III do $\S 2^{\circ}$ do art. 198 e o art. 212 da Constituição Federal;

II - receitas que pertencem aos Municípios decorrentes de transferências previstas na Constituição Federal;

III - receitas de contribuições previdenciárias e de assistência à saúde dos servidores;

IV - demais transferências obrigatórias e voluntárias entre entes da Federação com destinação especificada em lei. (acrescentado pela EC No. 93/2016)

Art. 76-B. São desvinculados de órgão, fundo ou despesa, até 31 de dezembro de 2023, $30 \%$ (trinta por cento) das receitas dos Municípios relativas a impostos, taxas e multas, já instituídos ou que vierem a ser criados até a referida data, seus adicionais e respectivos acréscimos legais, e outras receitas correntes.

Parágrafo único. Excetuam-se da desvinculação de que trata o caput:

I - recursos destinados ao financiamento das ações e serviços públicos de saúde e à manutenção e desenvolvimento do ensino de que tratam, respectivamente, os incisos II e III do $\S 2^{\circ}$ do art. 198 e o art. 212 da Constituição Federal;

II - receitas de contribuições previdenciárias e de assistência à saúde dos servidores;

III - transferências obrigatórias e voluntárias entre entes da Federação com destinação especificada em lei; (acrescentado pela EC No. 93/2016) 
Art. 79. É instituído, para vigorar até o ano de 2010, no âmbito do Poder Executivo Federal, o Fundo de Combate e Erradicação da Pobreza, a ser regulado por lei complementar com o objetivo de viabilizar a todos os brasileiros acesso a níveis dignos de subsistência, cujos recursos serão aplicados em ações suplementares de nutrição, habitação, educação, saúde, reforço de renda familiar e outros programas de relevante interesse social voltados para melhoria da qualidade de vida.

Parágrafo único. $O$ Fundo previsto neste artigo terá Conselho Consultivo e de Acompanhamento que conte com a participação de representantes da sociedade civil, nos termos da lei.

Art. 80. Compõem o Fundo de Combate e Erradicação da Pobreza:

I - a parcela do produto da arrecadação correspondente a um adicional de oito centésimos por cento, aplicável de 18 de junho de 2000 a 17 de junho de 2002, na alíquota da contribuição social de que trata 0 art. 75 do Ato das Disposições Constitucionais Transitórias;

II - a parcela do produto da arrecadação correspondente a um adicional de cinco pontos percentuais na alíquota do Imposto sobre Produtos Industrializados - IPI, ou do imposto que vier a substituí-lo, incidente sobre produtos supérfluos e aplicável até a extinção do Fundo;

III - o produto da arrecadação do imposto de que trata o art. 153, inciso VII, da Constituição;

IV - dotações orçamentárias;

V - doações, de qualquer natureza, de pessoas físicas ou jurídicas do País ou do exterior;

VI - outras receitas, a serem definidas na regulamentação do referido Fundo.

$\S 1^{\circ}$ Aos recursos integrantes do Fundo de que trata este artigo não se aplica o disposto nos arts. 159 e 167, inciso IV, da Constituição, assim como qualquer desvinculação de recursos orçamentários.

$\S 2^{\circ}$ A arrecadação decorrente do disposto no inciso I deste artigo, no período compreendido entre 18 de junho de 2000 e o início da vigência da lei complementar a que se refere a art. 79, será integralmente repassada ao Fundo, preservado o seu valor real, em títulos públicos federais, progressivamente resgatáveis após 18 de junho de 2002, na forma da lei.

Art. 81. É instituído Fundo constituído pelos recursos recebidos pela União em decorrência da desestatização de sociedades de economia mista ou empresas públicas por ela controladas, direta ou indiretamente, quando a operação envolver a alienação do respectivo controle acionário a pessoa ou entidade não integrante da Administração Pública, ou de participação societária remanescente após a alienação, cujos rendimentos, gerados a partir de 18 de junho de 2002, reverterão ao Fundo de Combate e Erradicação de Pobreza.

$\S 1^{\circ}$ Caso o montante anual previsto nos rendimentos transferidos ao Fundo de Combate e Erradicação da Pobreza, na forma deste artigo, não alcance o valor de quatro 
bilhões de reais, far-se-á complementação na forma do art. 80 , inciso IV, do Ato das disposições Constitucionais Transitórias.

$\S 2^{\circ}$ Sem prejuízo do disposto no $\S 1^{\circ}$, o Poder Executivo poderá destinar ao Fundo a que se refere este artigo outras receitas decorrentes da alienação de bens da União.

$\S 3^{\circ} \mathrm{A}$ constituição do Fundo a que se refere o caput, a transferência de recursos ao Fundo de Combate e Erradicação da Pobreza e as demais disposições referentes ao § $1^{\circ}$ deste artigo serão disciplinadas em lei, não se aplicando o disposto no art. $165, \S 9^{\circ}$, inciso II, da Constituição.

Art. 82. Os Estados, o Distrito Federal e os Municípios devem instituir Fundos de Combate à Pobreza, com os recursos de que trata este artigo e outros que vierem a destinar, devendo os referidos Fundos ser geridos por entidades que contem com a participação da sociedade civil.

$\$ 1^{\circ}$ Para o financiamento dos Fundos Estaduais e Distrital, poderá ser criado-adicional de até dois pontos percentuais na alíquota do Imposto sobre Circulação de Mercadorias e Serviços-ICMS, ou do imposto que vier a substituí-lo, sobre os produtos e serviços supérfluos, não se aplicando, sobre este adicional, o disposto no art. 158, inciso IV, da Constituição.

$\S 1^{\circ}$ Para o financiamento dos Fundos Estaduais e Distrital, poderá ser criado adicional de até dois pontos percentuais na alíquota do Imposto sobre Circulação de Mercadorias e Serviços - ICMS, sobre os produtos e serviços supérfluos e nas condições definidas na lei complementar de que trata 0 art. $155, \S 2^{\circ}$, XII, da Constituição, não se aplicando, sobre este percentual, o disposto no art. 158, IV, da Constituição. (alterado pela EC No. 42/2003)

$\S 2^{\circ}$ Para o financiamento dos Fundos Municipais, poderá ser criado adicional de até meio ponto percentual na alíquota do Imposto sobre serviços ou do imposto que vier a substituí-lo, sobre serviços supérfluos.

Art. 83. Lei federal definirá os produtos e serviços supérfluos a que se referem os arts. 80, inciso II, e $\mathbf{8 2}, \S \S 1^{\circ}$ e $2^{\circ}$. (Os artigos 79 a 83 foram acrescentados pela EC No. 31, de 2000, prorrogada por tempo indeterminado pela EC No. 67/2010)

Art. 83. Lei federal definirá os produtos e serviços supérfluos a que se referem os arts. 80, II, e 82, § $\mathbf{2}^{\circ}$. (alterado pela EC No. 42/2003)

Art. 106. Fica instituído o Novo Regime Fiscal no âmbito dos Orçamentos Fiscal e da Seguridade Social da União, que vigorará por vinte exercícios financeiros, nos termos dos arts. 107 a 114 deste Ato das Disposições Constitucionais Transitórias.

Art. 107. Ficam estabelecidos, para cada exercício, limites individualizados para as despesas primárias:

$\S 1^{\circ}$ Cada um dos limites a que se refere o caput deste artigo equivalerá:

I - para o exercício de 2017, à despesa primária paga no exercício de 2016 , incluídos os restos a pagar pagos e demais operações que afetam o resultado primário, corrigida em $7,2 \%$ (sete inteiros e dois décimos por cento); e

II - para os exercícios posteriores, ao valor do limite referente ao exercício 
O Financiamento da Educação na Constituição Federal de 1988 e suas Alterações até Abril de 2018

imediatamente anterior, corrigido pela variação do Índice Nacional de Preços ao Consumidor Amplo - IPCA, publicado pelo Instituto Brasileiro de Geografia e Estatística, ou de outro índice que vier a substituí-lo, para o período de doze meses encerrado em junho do exercício anterior a que se refere a lei orçamentária.

Art. 110. Na vigência do Novo Regime Fiscal, as aplicações mínimas em ações e serviços públicos de saúde e em manutenção e desenvolvimento do ensino equivalerão:

I - no exercício de 2017, às aplicações mínimas calculadas nos termos do inciso I do §

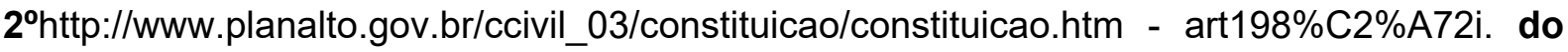
art. 198 e do caput do art. 212 da Constituição Federal; e

II - nos exercícios posteriores, aos valores calculados para as aplicações mínimas do exercício imediatamente anterior, corrigidos na forma estabelecida pelo inciso II do § $1^{\circ}$ do art. 107 deste Ato das Disposições Constitucionais Transitórias. (acrescentado pela EC No. 95/2016)

\section{Referências}

BRASIL. Constituição da República Federativa do Brasil. Diário Oficial da União, Brasília, Senado Federal, 1988. Disponível em: <http://www. planalto.gov.br>. Acesso em: 7 maio 2018.

BRASIL. Emenda Constitucional de Revisão No. 1, de 1/3/1994. Acrescenta os arts. 71, 72 e 73 ao ADCT. Diário Oficial da União, Brasília, 1994. Disponível em: <http://www. planalto.gov.br>. Acesso em: 7 maio 2018.

BRASIL. Emenda Constitucional No. 10, de 4/3/1996. Altera os arts. 71 e 72 do ADCT, introduzidos pela Emenda Constitucional de Revisão n 1, de 1994. Diário Oficial da União, Brasília, 1996. Disponível em: <http://www.planalto.gov.br>. Acesso em: 7 maio 2018.

BRASIL. Emenda Constitucional No. 14, de 12/9/1996. Modifica os arts. 34, 208, 211 e 212 da Constituição Federal e dá nova redação ao art. 60 do ADCT. Diário Oficial da União, Brasília, 1996. Disponível em: <http://www.planalto.gov.br>. Acesso em: 7 maio 2018.

BRASIL. Emenda Constitucional No. 17, de 22/11/1997. Altera dispositivos dos arts. 71 e 72 do ADCT, introduzidos pela Emenda Constitucional de Revisão $n^{\circ} 1$, de 1994. Diário Oficial da União, Brasília, 1997. Disponível em: <http://www.planalto.gov.br>. Acesso em: 7 maio 2018.

BRASIL. Emenda Constitucional No. 19, de 4/6/1998. Modifica o regime e dispõe sobre princípios e normas da Administração Pública, servidores e agentes políticos, controle de despesas e finanças públicas e custeio de atividades a cargo do Distrito Federal, e dá outras providências. Diário Oficial da União, Brasília, 1998. Disponível em: <http://www.planalto.gov.br>. Acesso em: 7 maio 2018.

BRASIL. Emenda Constitucional No. 27, de 21/3/2000. Acrescenta o art. 76 ao ADCT, instituindo a desvinculação de arrecadação de impostos e contribuições sociais da União. Diário Oficial da União, Brasília, 2000. Disponível em: <http://www.planalto.gov.br>. Acesso em: 7 maio 2018.

BRASIL. Emenda Constitucional No. 29, de 13/9/2000. Altera os arts. 34, 35, 156, 160, 167 e 198 da Constituição Federal e acrescenta artigo ao ADCT, para assegurar os recursos 
O Financiamento da Educação na Constituição Federal de 1988 e suas Alterações até Abril de 2018

mínimos para o financiamento das ações e serviços públicos de saúde. Diário Oficial da União, Brasília, 2000. Disponível em: <http://www.planalto.gov.br>. Acesso em: 7 maio 2018.

BRASIL. Emenda Constitucional No. 31, de 14/12/2000. Altera o ADCT, introduzindo artigos que criam o Fundo de Combate e Erradicação da Pobreza. Diário Oficial da União, Brasília, 2000. Disponível em: <http://www.planalto.gov.br>. Acesso em: 7 maio 2018.

BRASIL. Emenda Constitucional No. 42, de 19/12/2003. Altera o Sistema Tributário Nacional e dá outras providências. Diário Oficial da União, Brasília, 2003. Disponível em: <http://www.planalto.gov.br>. Acesso em: 7 maio 2018.

BRASIL. Emenda Constitucional No. 53, de 19/12/2006. Dá nova redação aos arts. $7^{\circ}, 23,30$, 206, 208, 211 e 212 da Constituição Federal e ao art. 60 do ADCT. Diário Oficial da União, Brasília, 2006. Disponível em: <http://www.planalto.gov.br>. Acesso em: 7 maio 2018.

BRASIL. Emenda Constitucional No. 56, de 20/12/2007. Prorroga o prazo previsto no caput do art. 76 do ADCT e dá outras providências. Diário Oficial da União, Brasília, 2007.

BRASIL. Emenda Constitucional No. 59, de 11/11/2009. Acrescenta $\S 3^{\circ}$ ao art. 76 do ADCT para reduzir, anualmente, a partir do exercício de 2009, o percentual da Desvinculação das Receitas da União incidente sobre os recursos destinados à manutenção e desenvolvimento do ensino de que trata o art. 212 da Constituição Federal, dá nova redação aos incisos I e VII do art. 208, de forma a prever a obrigatoriedade do ensino de quatro a dezessete anos e ampliar a abrangência dos programas suplementares para todas as etapas da educação básica, e dá nova redação ao $\S 4^{\circ}$ do art. 211 e ao $\S 3^{\circ}$ do art. 212 e ao caput do art. 214, com a inserção neste dispositivo de inciso VI. Diário Oficial da União, Brasília, 2009. Disponível em: <http://www.planalto.gov.br>. Acesso em: 7 maio 2018.

BRASIL. Emenda Constitucional No. 67, de 22/12/2010. Prorroga, por tempo indeterminado, o prazo de vigência do Fundo de Combate e Erradicação da Pobreza. Diário Oficial da União, Brasília, 2010. Disponível em: <http://www.planalto.gov.br>. Acesso em: 7 maio 2018.

BRASIL. Emenda Constitucional No. 68, de 21/12/2011. Altera o art. 76 do ADCT. Diário Oficial da União, Brasília, 2011. Disponível em: <http://www.planalto.gov.br>. Acesso em: 7 maio 2018.

BRASIL. Emenda Constitucional No. 85, de 26/2/2015. Altera e adiciona dispositivos na Constituição Federal para atualizar o tratamento das atividades de ciência, tecnologia e inovação. Diário Oficial da União, Brasília, 2015. Disponível em: <http://www.planalto.gov.br>. Acesso em: 7 maio 2018.

BRASIL. Emenda Constitucional No. 93, de 8/9/2016. Altera o ADCT para prorrogar a desvinculação de receitas da União e estabelecer a desvinculação de receitas dos Estados, Distrito Federal e Municípios. Diário Oficial da União, Brasília, 2016. Disponível em: <http://www.planalto.gov.br>. Acesso em: 7 maio 2018.

BRASIL. Emenda Constitucional No. 95, de 15/12/2016. Altera o Ato das Disposições Constitucionais Transitórias (ADCT), para instituir o Novo Regime Fiscal, e dá outras providências. Diário Oficial da União, Brasília, 2016. Disponível em: <http://www.planalto.gov.br>. Acesso em: 7 maio 2018. 
O Financiamento da Educação na Constituição Federal de 1988 e suas Alterações até Abril de 2018

Nicholas Davies possui graduação em História pela Universidade Federal Fluminense (1983), mestrado em educação pela Universidade Federal Fluminense (1991) e doutorado em sociologia pela Universidade de São Paulo (1999). Atualmente é professor titular aposentado da Universidade Federal Fluminense. Tem experiência na área de Educação, com ênfase em política educacional, atuando principalmente nos seguintes temas: financiamento da educação, fundef, fundeb, orçamento da educação, público/privado, legislação educacional, livro didático e ensino de história.

E-mail: nidavies1@hotmail.com 


\title{
Editores do volume 8
}

José Marcelino de Rezende Pinto - Universidade de São Paulo, São Paulo/SP, Brasil

Nalú Farenzena - Universidade Federal do Rio Grande do Sul, Porto Alegre/RS, Brasil

\section{Comitê Editorial}

José Marcelino de Rezende Pinto - Universidade de São Paulo, Brasil

Juca Gil - Universidade Federal do Rio Grande do Sul, Brasil

Theresa Adrião - Universidade Estadual de Campinas, Brasil Ângelo

Ricardo de Souza - Universidade Federal do Paraná, Brasil

Márcia Aparecida Jacomini - Universidade Federal de São Paulo, Brasil

\section{Conselho Editorial}

\section{Alejandro Morduchowicz}

Universidad Pedagógica, Provincia de Buenos Aires, Argentina

Fernanda Saforcada

Universidade de Buenos Aires, Argentina

Jacques Velloso

Universidade de Brasília, Brasil

João Monlevade

Senado Federal, Brasil

Jorge Abrahão de Castro

Instituto de Pesquisa Econômica Aplicada / IPEA, Brasil

Juca Gil

Universidade Federal do Rio Grande do Sul, Brasil

Lisete Regina Gomes Arelaro

Universidade de São Paulo, Brasil

Luis Carlos Sales

Universidade Federal do Piauí, Brasil

Luiz de Sousa Junior

Universidade Federal da Paraíba, Brasil

Luiz Fernandes Dourado

Universidade Federal de Goiás, Brasil

Magna França

Universidade Federal do Rio Grande do Norte, Brasil

\section{Maria Beatriz Luce}

Universidade Federal do Pampa, Brasil

Universidade Federal do Rio Grande do Sul, Brasil

Marcos Edgar Bassi

Universidade Federal do Paraná, Brasil

\author{
Maria Dilnéia Espíndola Fernandes \\ Universidade Federal de Mato Grosso do Sul, Brasil \\ Nalú Farenzena \\ Universidade Federal do Rio Grande do Sul, Brasil \\ Nelson Cardoso do Amaral \\ Universidade Federal de Goiás, Brasil \\ Nicholas Davies \\ Universidade Federal Fluminense, Brasil \\ Rosana Evangelista Cruz \\ Universidade Federal do Piauí, Brasil \\ Rosana Gemaque \\ Universidade Federal do Pará, Brasil \\ Robert E. Verhine \\ Universidade Federal da Bahia, Brasil \\ Romualdo Portela de Oliveira \\ Universidade de São Paulo, Brasil \\ Theresa Adrião \\ Universidade Estadual de Campinas, Brasil \\ Tristan McCowan \\ University of London, Reino Unido \\ Vera Jacob \\ Universidade Federal do Pará, Brasil \\ Vera Peroni \\ Universidade Federal do Rio Grande do Sul, Brasil \\ Vitor Henrique Paro \\ Universidade de São Paulo, Brasil
}

\section{Equipe editorial}

Apoio ao Comitê Editorial: Patrícia Balthazar Garcia

Diagramação, Revisão de português e normalização: Edson Leonel de Oliveira

Revisão de inglês: Ananyr Porto Fajardo 